Journal of Animal and Veterinary Advances 11 (10): 1588-1594, 2012

ISSN: $1680-5593$

(C) Medwell Journals, 2012

\title{
Effect of PPAR $\alpha$ 's over Expression on the Type 2 Diabetic Rat Cardiomyocytes
}

\author{
${ }^{1}$ Liang ZiWen, ${ }^{1} \mathrm{Wu}$ QiNan, ${ }^{2}$ Tang QiuShan, ${ }^{1}$ Chen Bing, \\ ${ }^{3} \mathrm{Wu}$ Ping, ${ }^{3} \mathrm{G}$ ao Yuan and ${ }^{3} \mathrm{Xiao}$ Qian \\ ${ }^{1}$ Department of Endocrine, The South West Hospital of the Third Military Medical University, \\ ${ }^{2}$ Department of Applied Anatomy and Operative Surgery, \\ The Third Military Medical University, Post Number: 400038, Chongqing, China \\ ${ }^{3}$ Department of Gerontal, The First Affiliated Hospital of Chongqing Medical University, \\ Post Number: 400016, Chongqing, China
}

\begin{abstract}
To investigate the over expression of PPAR $\alpha$ and trimetazidine in the apoptosis of rat cardiomyocyte with type 2 diabetes. All rats were divided into 3 groups: Group N (control group), Group D (type 2 diabetes group); Group T (type 2 diabetes which treated by trimetazidine). After 16 weeks breeding, apoptosis of each group were detected by TUNEL, ultrastructure were detected by electronic microscope, immunohistochemistry staining and western blotting were used to detected each group's cardiomyocyte about PPAR $\alpha$ and NF- $\mathrm{kB}$ in the expression of each protein level. The number of apoptosis was increased in Group D and the ultra structure was changed, the expression of PPAR $\alpha$ in protein level was decreased also the NF- $\mathrm{KB}(\mathrm{p}<0.05)$. After treated by trimetazidine in type 2 diabetic rat, the apoptosis of cardiomyocytes was decreased distinctly $(\mathrm{p}<0.05)$, the change of ultra structure was improved, the expression of PPAR $\alpha$ and NF- $\mathrm{kB}$ were all decreased in protein level $(\mathrm{p}<0.05)$. The over expression of PPAR $\alpha$ might be involved in the regulation of the apoptosis in cardiomyocyte and the ultrastructual change of diabetic cardiomyopathy, suggesting it may participate in the development of diabetic cadiomyopathy and treated by trimetazidine may reverse it.
\end{abstract}

Key words: Apoptosis, diabetic cadiomyopathy, peroxisome proliferator activated receptor $\alpha$, trimetazidine, protein

\section{INTRODUCTION}

Cardiomyocyte apoptosis in diabetes is one of the important events in diabetic heart failure. This process is regulated by a series of gene. PPAR $\alpha$ is one of the member of nuclear receptor superfamily, it can interact with its upper reaches of the specificity of certain DNA response element (Peroxisome Proliferators Responsive Element, PPRE), activate nuclear transcription control mechanisms and control of gene expression, play a key role in the regular of the oxidative metabolism of fatty acids and cell proliferation, apoptosis (Lefebvre et al., 2006). Young et al. (2001) showed that the $\operatorname{PPAR} \alpha$ agonist can activated pressure overload cardiomyopathy and induced cardiomyocyte apoptosis resulting in mice heart failure. Dyntar et al. (2001) find that $\operatorname{PPAR} \alpha$ expression level increases in Streptozotocin (STZ)-induced diabetic rat myocardium which resulting in the changes of key enzyme in glucose and lipid metabolism and induced cardiac cell apoptosis. Some researchers pointed out the mice which over expression the PPAR $\alpha$ (Myosin Heavy Chain (MHC)-PPAR mice) have the similar cardiac energy metabolism disorder and cardiac cell damage in diabetic rat (Dyntar et al., 2001; Finck et al., 2003). These researches have proved that over expression of PPAR $\alpha$ may lead to cardiac cell apoptosis and even heart failure in diabetic model but the mechanism is not clearly. Based on these, researchers choosed the type 2 diabetic rats which induced by low dose STZ and high-fat diet. And treated with trimetazidine, the 3-Acyl-CoA S-transferase inhibitor which has been widely used in coronary heart disease, myocardial ischemia and other heart disease, it can reverse the cell damage which induced by the myocardial energy metabolism disorder and prevent the occurrence of advanced cardiovascular events effectively (Aussedat et al., 2006; Tabbi-Anneni et al., 2003). And detected the expression of PPAR $\alpha, \mathrm{NF}-\mathrm{kB}$, ultra structure

Corresponding Author: Chen Bing, Department of Endocrine, The South West Hospital of the Third Military Medical University, Post Number: 400016, Chongqing, China 
and apoptosis of each group's cardiomyocyte, aimed to reveal the connection and mechanism between the over-expression of $\operatorname{PPAR} \alpha$ and the cardiomyocyte apoptosis in diabetic cardiomyopathy.

\section{MATERIALS AND METHODS}

Experimental animal groups and modeling: SD male rats 30 (from the Third Military Medical University Animal Center). Weighing about $250 \mathrm{~g}$, they were divided into 3 groups by the random number law: normal group (fed basis food, 10, $\mathrm{N}$ group), diabetes (high fat diet feeding and low dose STZ, 10, Group D) and drug intervention group (low dose STZ, high fat diet and treated by Trimetazidine, 10, T group), the basis food of protein, fat, carbohydrates were $(\mathrm{w} / \mathrm{w}) 21.9,15.5,62.6 \%$; high-fat diet of protein, fat, carbohydrates were (w/w) 11.3, 43.6, 45.1\%. Intraperitoneal injection, high fat diet feeding 4 weeks post-test blood glucose, blood glucose $16.7 \mathrm{mmol} \mathrm{L}^{-1}$ is the judgment for type 2 diabetes and continued high fat diet feeding 8 weeks (Chen et al., 2004), drug treat group in a model of diabetic rats fed high-fat diet and feed trimetazidine $7.5 \mathrm{mg}$ day $^{-1}$ (add in the food) 8 weeks (Tabbi-Anneni et al., 2003).

Specimens collected and stored: After 16 weeks feeding, Group D and $\mathrm{N}$ rats did high insulin-normal glucose clamp (EICT) to detect the IR and then, on the condition of asepsis, researchers took the cardiac muscle, use sliver paper parcels the heart tissue and keep it in refrigerators at $-80^{\circ} \mathrm{C}$; three groups detect the cardiomyocyte apoptosis rate by TUNEL at the same time and electron microscope was used to detect the change of ultra structural situation.

High insulin-normal glucose clamp (EICT): The rats were fasted for 12-14 $\mathrm{h}$ overnight before the clamp study began the next morning. Rats were anesthetized by the intraperitoneal injection of amobarbital sodium ( $25 \mathrm{mg} \mathrm{kg}^{-1}$ ) which individualized to each subject's body weight. Rats were punctured in the right jugular vein for infusion of glucose and insulin (using separate lines) and in the left carotid artery for blood sampling. Two digital syringe pumps jointed by a $\mathrm{Y}$ connector to the jugular catheter which stored the glucose and insulin solutions each.

Insulin (Humulin R, Lilly, France SAS) was infused at a rate of $1.67 \mathrm{mU} / \mathrm{kg} / \mathrm{min}$ through the jugular vein catheter from $0-120 \mathrm{~min}$. Glucose concentrations were clamped at euglycemic levels $\left((5.0 \pm 0.5) \mathrm{mmol} \mathrm{L}^{-1}\right)$ by a variable rate infusion of $10 \%$ glucose. Blood glucose levels were serially monitored $w$ ith a Glucometer (Lifescan, USA) and Glucose Infusion Rates (GIR) were adjusted every 5-10 min as needed to maintain the blood glucose at euglycemic levels $\left(5.0 \pm 0.5 \mathrm{mmol} \mathrm{L}^{-1}\right)$. Clamping was achieved by $90 \mathrm{~min}$ and maintained for $30 \mathrm{~min}$. The mean GIR was calculated based on GIR readings corresponding to the last 8 samplings over $90-120 \mathrm{mg} / \mathrm{kg} / \mathrm{min}$ (Chen et al., 2004).

Immunohistochemical detection of the expression of PPAR $\alpha$ : Myocardial tissue removed, embedded in paraffin sections after conventional serum gamma dew axing closed to water, $3 \%$ hydrogen peroxide elimination of exogenous catalase with $0.01 \mathrm{~mol} \mathrm{~L}^{-1}$ of PBS after washing 3 times by adding to 1:200 dilution of goat anti-rat cardiac-specific PPAR $\alpha$ antibody (SANTACRUZE original, rat anti-goat) were incubated overnight at $4^{\circ} \mathrm{C}$.

Then, with 1:100 dilution respectively HRP labeled goat anti-rabbit IgG antibody (SANTACRUZE companies, Beijing Zhongshan Biotechnology Limited packed) were incubated for $1 \mathrm{~h}$. At last, DAB staining the sections. The staining of cardiomyocytes were detected at $250 \mathrm{x}$ magnification in light microscopy.

Detection of ultra structural situation: The fragments were cut into $1 \mathrm{~mm}$ cubic pieces which were soaked in $1 \%$ $\mathrm{OSO}_{4}$ solution for $2 \mathrm{~h}$ at $4^{\circ} \mathrm{C}$ and then dehydrated and embedded in araldite. Silver or gray thin sections $(60-90 \mathrm{~mm})$ were selected and cut on a Porter-Blum MT-B ultra microtome, mounted on copper silver grids with 200 patches and stained with uranyl acetate and lead citrate. The samples were selected, collected and deposed on copper wire with 200 patches. The preparations were examined with an electronic microscope (Model EM 90, Carl Zeiss) using a tension of $80 \mathrm{kV}$.

Detection of apoptosis: PBS will be organized by washing three times after the $4 \%$ more than in the POM fixed $25 \mathrm{~min}$ was detected by TUNEL apoptosis, the kit used by the Nanjing Kai Ji Biological Limited. Proteinase K digestion will be used after the biopsy of coverage by TUNEL, $37^{\circ} \mathrm{C}$ incubated for $90 \mathrm{~min}$; SSC termination reaction, antibodyHRP incubated $15 \mathrm{~min}$ at room temperature, PBS washed $\mathrm{DAB}$ colorimetric.

Light microscopy showed apoptotic cells depth varying brown. Semi-quantitative analysis of apoptotic cells: according distribution of apoptotic cells in 400 times the light microscope, each slice shooting seven positive vision, each counting 200 myocardial per-vision to calculate the average percentage of apoptotic cells as a down-death index.

Western blot analysis: Nucleus protein were diluted 1:1.5 in SDS-Laemmli buffer (30) and boiled for $5 \mathrm{~min}$. Equivalent amounts of each treatment group were run on 
$10 \%$ SDS polyacrylamide gels. Proteins were transferred electrically $(12 \mathrm{~V}, 30 \mathrm{~min})$ to PVDF membrane and incubated with a rat anti-goat $\operatorname{PPAR} \alpha, \mathrm{NF}-\kappa \mathrm{B}$ (P65) and $\beta$-actin polyclonal antibody (1:300, Santa Cruz Biotechnology, Santa Cruz, CA; 2 h at $37^{\circ} \mathrm{C}$ ).

After 3 times washed with TBST followed by incubation with goat radish Streptavidin-HRP-linked antimouse IgG (1:600, Santa Cruz Biotechnology, Santa Cruz, $\mathrm{CA} ; 2 \mathrm{~h}$ at $37^{\circ} \mathrm{C}$ ). After Lumiglo reagent (Photo tope-HRP Western blot Detection kit; Biolabs, Beverly, MA) was added, the emitted light was captured on X-ray film. Densitometric analysis was performed with quantity one software.

Statistical analysis: All results were analyzed by Spss13.0 Software. Data were analyzed by 1-factor Analysis of Variance (ANOVA). If a statistically significant effect was found, the Newman-Keuls test was performed to isolate the difference between the groups. The $\mathrm{p}<0.05$ were considered as indicative of significance.

\section{RESULTS}

Rats GIR: The determination of $\mathrm{N}$ rats average GIR was $12.3 \pm 4.14 \mathrm{mg} \mathrm{kg}^{-1} \mathrm{~min}, \mathrm{D}$ rats GIR average for $6.37 \pm 1.90 \mathrm{mg} \mathrm{kg}^{-1} \mathrm{~min}$, there are significant differences between the two groups, $\mathrm{p}<0.01$, the high note a small amount of fat diet feeding + STZ can successfully established type 2 diabetes rat model (Table 1).

\section{Apoptosis rate, ultra structure and PPAR, NF-kB's protein expression \\ Apoptosis: Compared with Group $\mathrm{N}$ and D, N group rarely} have the apoptosis of cells, organization arranged neatly (Fig. 1 and 2); Group D have more apoptotic cells than group $\mathrm{N}$, organizations arranged disorder (Fig. 2 and 3, $\mathrm{p}<0.05$, Table 2); compared with Group $\mathrm{D}$ and $\mathrm{T}$, cell apoptosis of $\mathrm{T}$ group was less than Group $\mathrm{D}$, organization arranged neatly (Fig. $1-3, \mathrm{p}<0.05$, Table 2 ).

Table 1: GR and glucose in D group compared with contras $(\overline{\mathrm{X}} \pm \mathrm{S}, \mathrm{n}=8)$

\begin{tabular}{lcc}
\hline Groups & GIR $\left(\mathrm{mg} \mathrm{kg}^{-1} \mathrm{~min}\right)$ & Glucose $\left(\mathrm{mmol} \mathrm{L}^{-1}\right)$ \\
$\mathrm{N}$ & $12.30 \pm 4.14$ & $5.21 \pm 1.74$ \\
$\mathrm{D}$ & $6.37 \pm 1.90^{*}$ & $19.70 \pm 3.28^{*}$ \\
\hline
\end{tabular}

Group N: *p<0.01

Table 2: The expression of PPAR $\alpha, N F-\kappa B$ in protein level and apoptosis rate in $N$ and $D$ group $(\overline{\mathrm{X}} \pm \mathrm{S})$

\begin{tabular}{lccc}
\hline Groups & $\begin{array}{c}\text { Apoptosis } \\
\text { rate } \mathrm{n}_{1}=7\end{array}$ & $\begin{array}{c}\text { The expression of nuclus } \\
\text { PPAR } \alpha \text { in protein level } \\
\text { of each group } \mathrm{n}_{2}=3\end{array}$ & $\begin{array}{c}\text { The expression of nuclus } \\
\text { NF- } \kappa \mathrm{B} \text { in protein level } \\
\text { of each groups } \mathrm{n}_{3}=3\end{array}$ \\
\hline $\mathrm{N}$ & $6.14 \pm 0.02$ & $0.3414 \pm 0.2502$ & $0.6209 \pm 0.0361$ \\
$\mathrm{D}$ & $45.71 \pm 0.04^{\mathrm{a}}$ & $1.9758 \pm 0.5682^{\mathrm{a}}$ & $2.7001 \pm 0.3860^{\mathrm{a}}$ \\
$\mathrm{T}$ & $27.43 \pm 0.03^{\mathrm{ab}}$ & $1.1704 \pm 0.2418^{\mathrm{ab}}$ & $1.231 \pm 0.21920^{\mathrm{ab}}$ \\
\hline
\end{tabular}

PPAR $\alpha$ 's protein expression: Group $N$ muscle fibers arranged neatly, PPAR $\alpha$ positive staining and expressing (Fig. 4, Table 2), Group D muscle fiber disarranged, $\operatorname{PPAR} \alpha$ positive staining were deeper than $\mathrm{N}$ group also the nuclear protein expression (Fig. 5-7, p<0.05, Table 2), Group T-myocardial PPAR $\alpha$ positive staining shallow than Group D a lso the nuclear protein expression $(\mathrm{p}<0.05$, Table 2$)$.

NF-kB's protein expression: The NF- $k B$ expression in the nuclear protein of Group D is higher than group $\mathrm{N}$ (Fig. 8, $\mathrm{p}<0.05$, Table 2). The NF- $\mathrm{kB}$ expression in the nuclear protein of Group D is higher than Group T (Fig. 8, p<0.05, Table 2). The NF-kB expression in the nuclear protein of Group $\mathrm{T}$ is higher than Group N (Fig. 8, p<0.05, Table 2).

Ultra structure: In Group $\mathrm{N}$, cardiomyocytes arranged regularly, intensive; in Group D, nuclear swelling, muscle

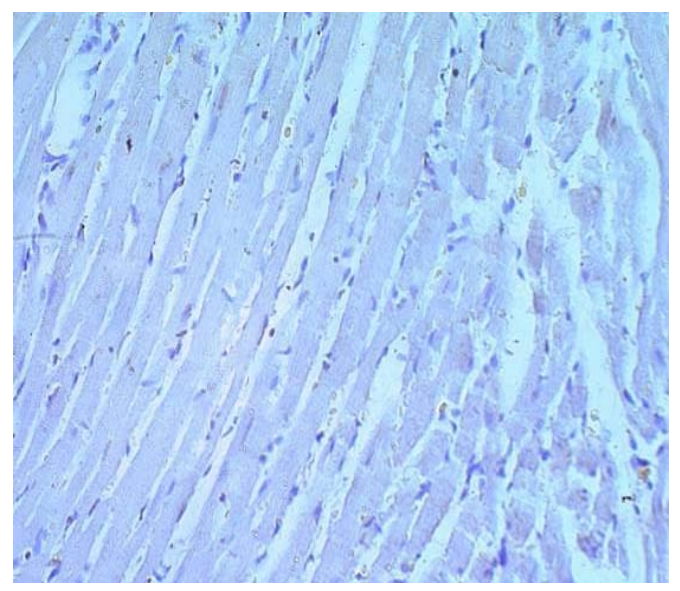

Fig. 1: The cardiomyocytes of $\mathrm{N}$ group TUNEL staining (x400)

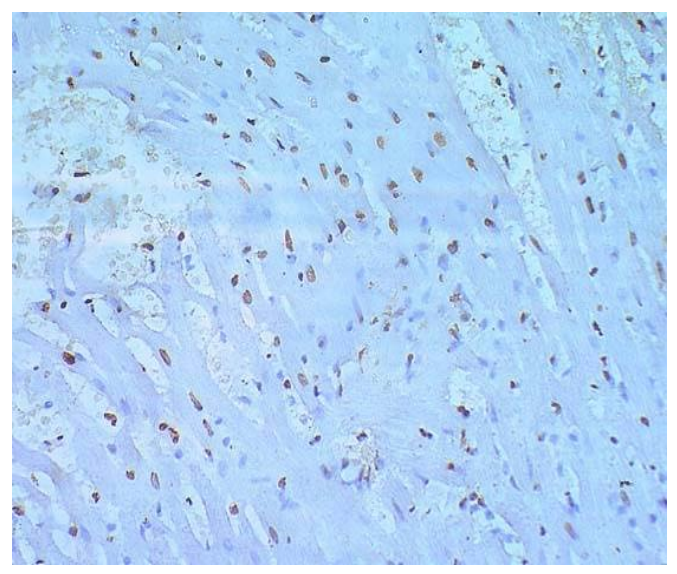

Fig. 2: The cardiomyocytes of D group TUNEL staining (x400) 


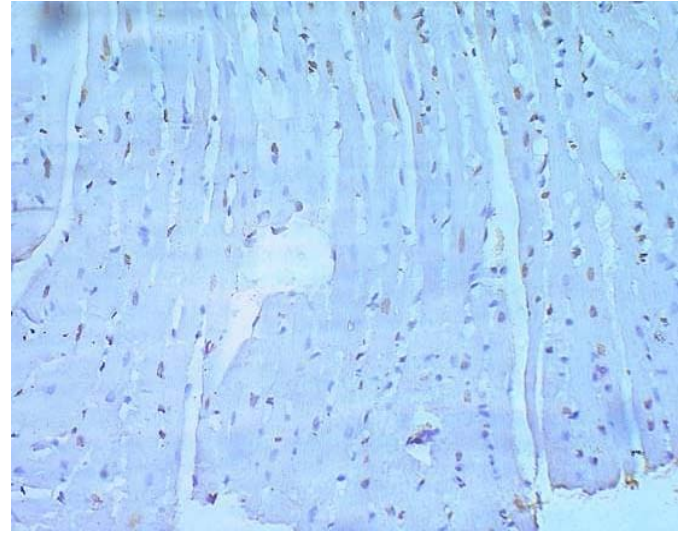

Fig. 3: The cardiomyocytes of T group; TUNEL staining $(\mathrm{x} 400)$

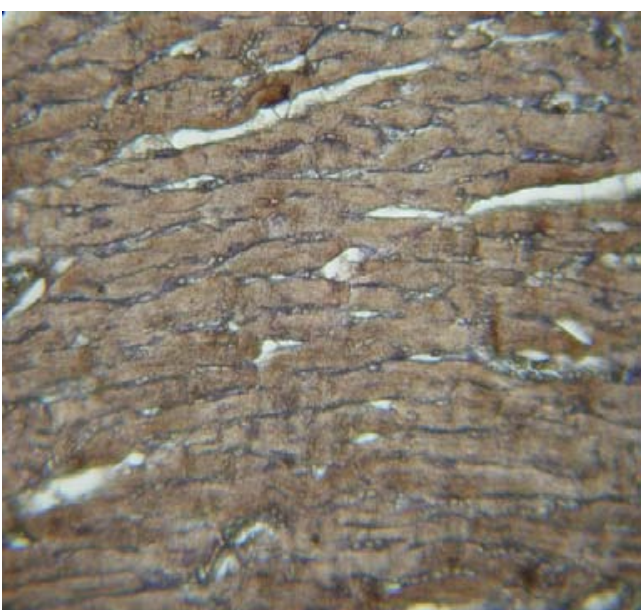

Fig. 4: Expression of PPAR $\alpha$ in cardiomuocytes of $\mathrm{N}$ group-immunohistochemistry staining (x250)

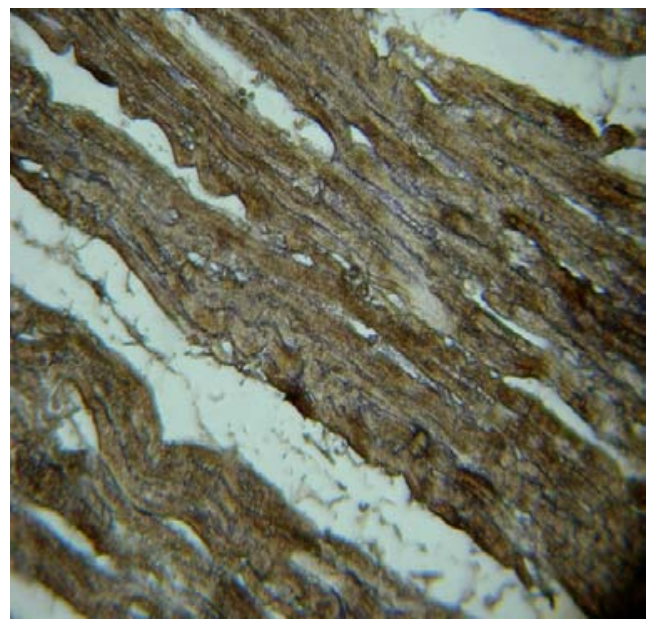

Fig. 5: Expression of PPAR $\alpha$ in cardiomuocytes of D group-immunohistochemistry staining (x250)

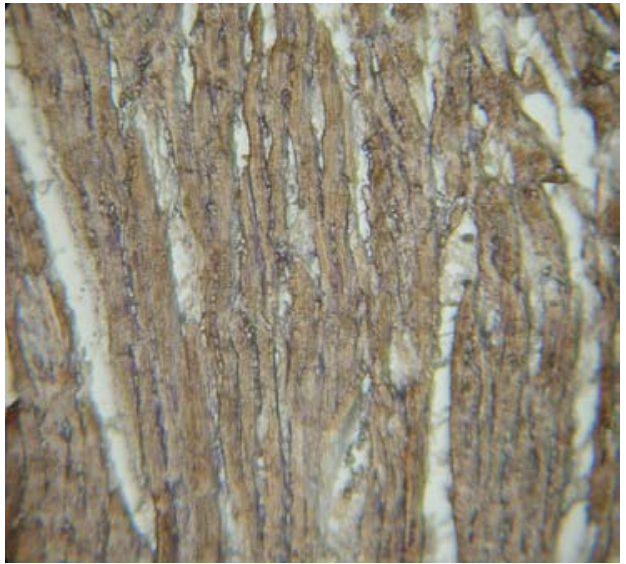

Fig. 6: Expression of PPAR $\alpha$ in cardiomuocytes of $\mathrm{T}$ group-immunohistochemistry staining (x250)

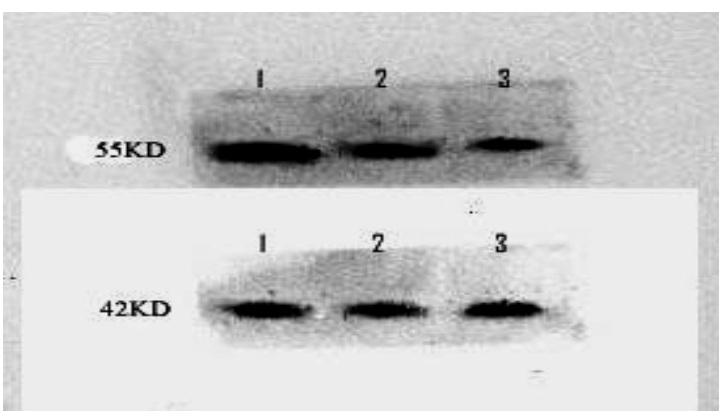

Fig. 7: The expression of nucleus PPAR $\alpha$ in protein level of each group-western blotting; $55 \mathrm{kD}$ : PPAR $\alpha$ $42 \mathrm{kD}$ : $\beta$-actin; Line 1: Group D; Line 2: Group T; Line 3: Group T

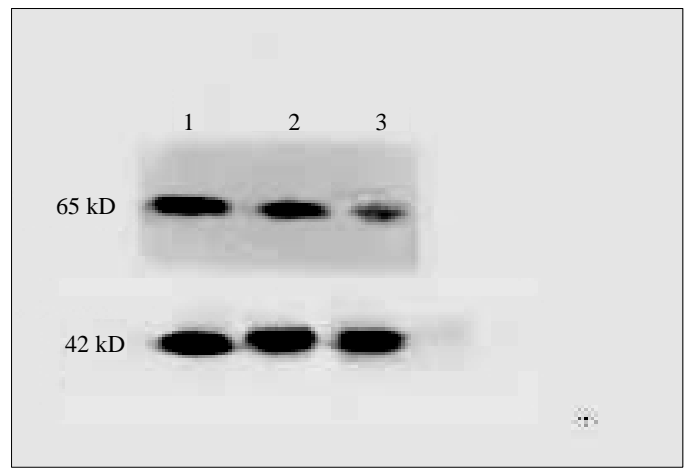

Fig. 8: The expression of nucleus NF- $\mathrm{kB}$ in protein level of each group-western blotting; $65 \mathrm{kD}$ : NF- $\mathrm{kB}$ $42 \mathrm{kD}$ : $\beta$-actin; Line 1: Group D; Line 2: Group T; Line 3: Group T

wire dissolved, fracture, the intermittent of disks are significantly expanded. In Group $\mathrm{T}$, cardiomyocytes were 


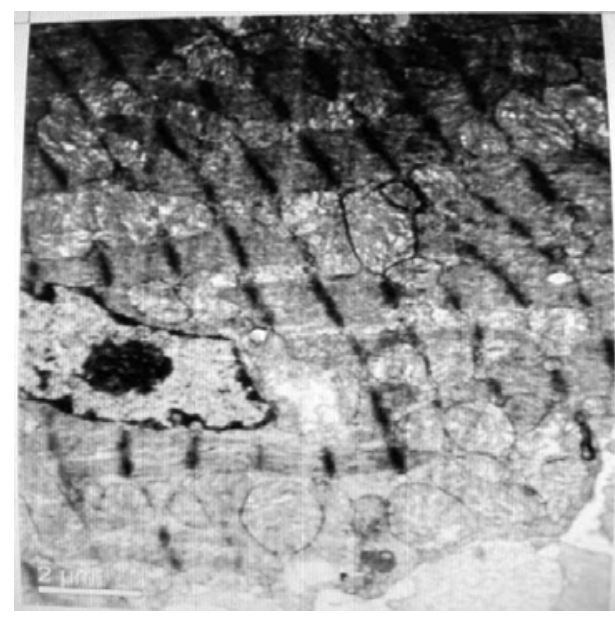

Fig. 9: Cardiac ultra structural of Group N (x8000)

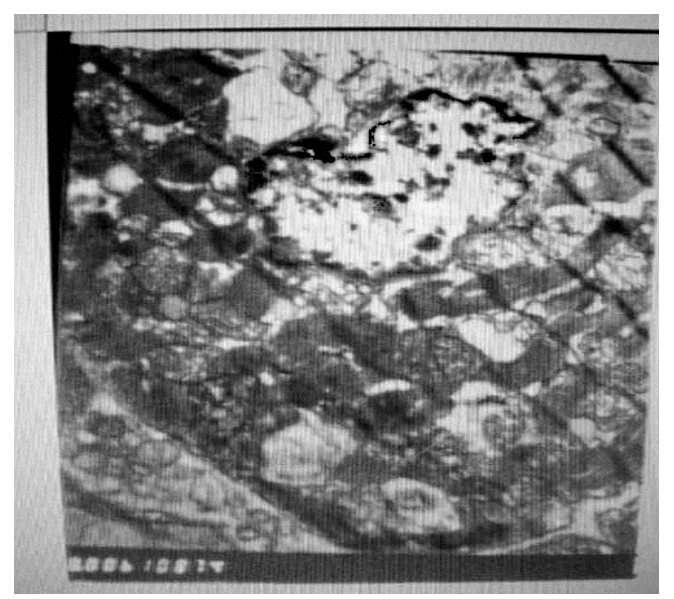

Fig. 10: Cardiac ultra structural changes of Group D (x8000)

basically normal, Z lines are less fuzzy and capillaries, muscle were more normal than Group D (Fig. 9-11).

The rate of apoptosis: Using Mann-Whitney $U$ Law, Group D vs. Group T: $z=-3.130, p=0.002$; Group D vs. Group N: $\mathrm{z}=-3.134, \mathrm{p}=0.002$; Group $\mathrm{T}$ vs. Group N: $\mathrm{z}=-3.07, \mathrm{p}=0.009$.

PPAR $\alpha$ 's optical density: A single-factor analysis of variance, $\mathrm{F}=170.311, \mathrm{p}=0.000$, using $\mathrm{SNK}$ law: $\mathrm{N}$ group vs. T group: $\mathrm{p}=0.041, \mathrm{t}=2.971 ; \mathrm{N}$ group vs. group $\mathrm{D}$ : $\mathrm{p}=0.002, \mathrm{t}=7.702$; $\mathrm{D}$ group vs. $\mathrm{T}$ group: $\mathrm{p}=0.014$, $\mathrm{t}=4.139$. NF-KB's optical density: a single-factor analysis of variance, $\mathrm{F}=181.259, \mathrm{p}=0.000$, using SNK law: $\mathrm{N}$ group vs. $D$ group: $\mathrm{p}=0.003, \mathrm{t}=7.528 ; \mathrm{N}$ group vs. the $\mathrm{T}$ group: $\mathrm{p}=0.002, \mathrm{t}=7.702 ; \mathrm{D}$ group vs. $\mathrm{T}$ group: $\mathrm{p}=0.018$, $\mathrm{t}=4.145$.

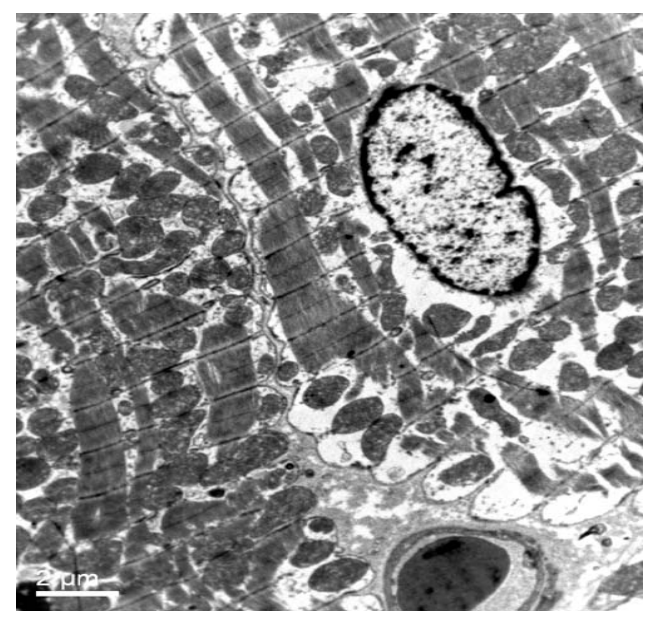

Fig. 11: Cardiac ultra structural changes of Group $\mathrm{T}$ (x8000)

\section{DISCUSSION}

Diabetic cardiomyopathy is one of the chronic cardiovascular complications of diabetes, it has been recognized since, 1974 but its mechanism has not yet been clarified. In recent years, many study found that apoptosis of cardiac cell and oxidative stress may play a key role in its process (Fang et al., 2004).

$\operatorname{PPAR} \alpha$ is mainly distributed in cardiac, skeletal muscle, liver and kidney tissues and play a key role in the activation of oxidative metabolism of fatty acids, cell proliferation and apoptosis (Lefebvre et al., 2006). Recent studies found that overexpression of PPAR $\alpha$ can change the myocardial energy supply mode and lead to cardiac myocyte apoptosis (Dyntar et al., 2001; Finck et al., 2003; Boudina and Abel, 2007; Indu et al., 2006). NF-kB can be activated by $\operatorname{PPAR} \alpha$ directly (Philippe Lefebvre et al., 2006 ) in the mediating of chronic inflammation, oxidative stress and apoptosis of cells directly or indirectly in many paths (Fang et al., 2004; Farhangkhoee et al., 2006; Matsuzawa, 2006). Many scholars believe that Type 2 Diabetes is a chronic inflammatory diseases, the activation of NF- $\mathrm{kB}$ and the increasing of oxidative stress level may stand an important position in the development of diabetes and its cardiovascular complications (Indu et al., 2006; Farhangkhoee et al., 2006; Matsuzawa, 2006).

Trimetazidine is widely used in the treatment in coronary heart disease and myocardial ischemia, its can block 3-Acyl-CoA S-transferase and inhibite the fatty acid oxidation, correct myocardial cell energy metabolism disorders, decrease the oxidative stress level and reduce the apoptosis of cardiac cell (Aussedat et al., 2006; 
Tabbi-Anneni et al., 2003; Rosano et al., 2003). In this experiment, compared to the Group N, the GIR of Group D is decreased and the blood glucose is increased, it has proved that researchers established the type 2 diabetic rat model successfully. In Group D, PPAR $\alpha$ is more expression than Group $\mathrm{N}(\mathrm{p}<0.05)$, the nuclear is swelling, muscle wire dissolved, fracture, the intermittent of disks are significantly expanded and TUNEL pictures show that Group D has the more cardiomyocyte apoptosis than the Group $\mathrm{N}(\mathrm{p}<0.05)$, so it has proved that the existence of diabetic cardiomyopathy in the diabtic rat model. From the Fig. 7 and 8 and Table 2, PPAR $\alpha$ 's expression of Group D are significantly higher than Group $\mathrm{N}$ also the $\mathrm{NF}-\mathrm{kB}$ and apoptotic cells in Group D is increasing compare with Group N $(\mathrm{p}<0.05)$.

It can prove that long perierd diabetes may induce the over expression of PPAR $\alpha$ and $\mathrm{NF}-\mathrm{kB}$, increase the apoptosis of cardiac cell and then change the cardiac ultra structure of diabetes rat. In the Group $\mathrm{T}$, we found that after the therapy of trimetazidine, compared to Group D, the apoptosis of cardiac cells decreased, cardiomyocytes and capillaries are normal, $\mathrm{Z}$ lines are less fuzzy, the expression of PPAR $\alpha$ is lower than Group D also the $\mathrm{NF}-\mathrm{KB}(\mathrm{p}<0.05)$, it can prove that trimetazidine may have improvement effect on the change of cardiac ultra structure of diabetic cardiomyopathy, decrease the apoptosis of cardiac cell in rat's diabetes rat and these effect may due to the reduction of over expressed PPAR $\alpha$ and the NF- $\mathrm{kB}$ downstream.

Although, the previous researches believed that the activation of PPAR $\alpha$ in cardiac cell has protective effect, this is also the theoretical basis of application of fibrates (Lefebvre et al., 2006). Recent studies suggested that over expression of PPAR $\alpha$ activate the downstream path of the fatty acid metabolism though the key enzyme MCPT-1 (carnitine Acyl-CoA transferase -1), FAT/CD36 (Acyl-transposition of enzyme) and promote the oxidation of free fatty acids. At the early stage of diabetes, it can compensate for the shortage of energy caused by the lack of glucose intake but the long-term over expression of $\operatorname{PPAR} \alpha$ may cause the providing of energy is depended on $\beta$-oxidation of fatty acid almost. This changing pattern of metabolism can cause myocardial cells and myocardial oxygen consumption increased, induce ROS accumulation and also the intracellular concentration ceramide increasing, endothelial Nitric Oxide (eNO) reduction inducible Nitric Oxide (iNO) increasing, all of these may induce the apoptosis of cardiac cell (Dyntar et al., 2001; Finck et al., 2003; How et al., 2006; Finck et al., 2003; Carley and Severson, 2005).

\section{CONCLUSION}

Through the experiment, researchers conclud that long-term diabetes metabolic disorder may cause the over-expression of PPAR $\alpha$ and the NF- $\mathrm{kB}$ downstream expression, it may be involved in the cardiac cells apoptosis and diabetic cardiomyopathy. The intervention of trimetazidine stand the anti-apoptotic role, it can reduce the excessive expression of PPAR $\alpha$ and NF- $\mathrm{KB}$, the mechinism may lies in the blockage of PPAR $\alpha$ can reverse fatty acid $\beta$-oxidation, corrected myocardial energy metabolism disorder, decrease the NF- $\mathrm{kB}$ expression, reducing myocardial oxygen consumption and superoxide clusters (ROS) aggregation (Lefebvre et al., 2006; Boudina and Abel, 2007; Indu et al., 2006; Farhangkhoee et al., 2006; Matsuzawa, 2006; Rosano et al., 2003).

\section{ACKNOWLEDGEMENTS}

This study was supported by research grants from the National Natural Science Foundation of China (No.: 30670838) and Health grants Council of Chongqing (07-2-78). Liang ZiWen and Wu QiNan are contributed equal to this research.

\section{REFERENCES}

Aussedat, J., A. Ray and L. Kay, 2006. Improvement of long term preservation of isolated arrested heart: Beneficial effect of ant ischemic agent trimetazidine. J. Cardiovasc. Pharmacol., 21: 128-128.

Boudina, S. and E.D. Abel, 2007. Diabetic cardiomyopathy revisited. Circulation, 115: 3213-3223.

Carley, A.N. and D.L. Severson, 2005. Fatty acid metabolism is enhanced in type 2 diabetic hearts. Biochim. Biophys. Acta., 1734: 112-126.

Chen, X.P., W.Y. Yang, S. Bu, J.Z. Xiao, X.L. Liu, N. Wang and W.H. Zhao, 2004. Effects of rosiglitazone and metformin on insulin resistance in high-fat diet rats. Zhonghua Nei Ke Xue Za Zhi, 43: $280-283$.

Dyntar, D., M. Eppenberger-Eberhardt, K. Maedler, M. Pruschy, H.M. Eppenberger, G.A. Spinas and M.Y. Donath, 2001. Glucose and palmitic acid induce degeneration of myofibrils and modulate apoptosis in rat adult cardiomyocytes. Diabetes, 50: 2105-2113.

Fang, Z.Y., J.B. Prins and T.H. Marwick, 2004. Diabetic cardiomyopathy: Evidence, mechanisms and therapeutic implications. Endocr. Rev., 25: 543-567.

Farhangkhoee, H., Z.A. Khan, S. Chen and S. Chakrabarti, 2006. Differential effects of curcumin on vasoactive factors in the diabetic rat heart. Nutrit. Metab., 10.1186/1743-7075-3-27. 
Finck, B.N., X. Han, M. Courtois, F. Aimond and J.M. Nerbonne et al., 2003. A critical role for $\operatorname{PPAR} \alpha$-mediated lipotoxicity in the pathogenesis of diabetic cardiomyopathy: Modulation by dietary fat content. Proc. Natl. Acad. Sci., 100: 1226-1231.

How, O.J., E. Aasum, D.L. Severson, W.Y. Chan, M.F. Essop and T.S. Larsen, 2006. Increased myocardial oxygen consumption reduces cardiac efficiency in diabetic mice. Diabetes, 55: 466-473.

Indu, G., P. Parikh, R.P. Shannon, 2006. Diabetic cardiomyopathy: The search for a unifying hypothesis. Circulation Res., 98: 596-605.

Lefebvre, P., G. Chinetti, J.C. Fruchart and B. Staels, 2006. Sorting out the roles of PPAR $\alpha$ in energy metabolism and vascular homeostasis. J. Clin. Invest., 116: $571-580$.
Matsuzawa, Y., 2006. The metabolic syndrome and adipocytokines. FEBS Lett., 580: 2917-2921.

Rosano, G.M., C. Vitale, B. Sposato, G. Mercuro and M. Fini, 2003. Trimetazidine improves left ventricular function in diabetic patients with coronary artery disease: A double-blind placebo-controlled study. Cardiovasc. Diabetol., 2: 16-16.

Tabbi-Anneni, I., C. Helies-Toussaint, D. Morin, A. Bescond-Jacquet, A. Lucien and A. Grynberg, 2003. Prevention of heart failure in rats by trimetazidine treatment: A consequence of accelerated phospholipid turnover? J. Pharmacol. Exp. Ther. Fast Forward, 304: 1003-1009.

Young, M.E., F.A. Laws, G.W. Goodwin and H. Taegtmeyer, 2001. Reactivation of peroxisome proliferator-activated receptor alpha is associated with contractile dysfunction in hypertrophied rat heart. J. Biol. Chem., 276: 44390-44395. 